\title{
Seasonal allergic rhinitis: fluticasone propionate and fluticasone furoate therapy evaluated
}

\author{
This article was published in the following Dove Press journal: \\ Journal of Asthma and Allergy \\ 2 July 2010 \\ Number of times this article has been viewed
}

\section{Harsha H Kariyawasam Glenis K Scadding}

Royal National Throat Nose and Ear Hospital and Royal Free Hospital NHS Trust University College London, UK
Correspondence: Glenis K Scadding Royal National Throat Nose and Ear Hospital, Department of Allergy and Medical Rhinology, 330 Gray's Inn Road, London, WCIX 8DA, UK

$\mathrm{Tel}+440207915 \quad 674$

Fax +440207915 1674

Email g.scadding@ucl.ac.uk
Abstract: Seasonal allergic rhinitis (SAR) is increasing in prevalence such that 1 in 4 persons is affected in the UK. It represents a considerable burden of disease since in a significant proportion of individuals the severity of nasal-ocular symptoms has an important effect on daily activity, performance and quality of life. Intranasal steroids (INS) form the mainstay of treatment, having been shown in meta-analyses to be superior to oral antihistamines, intranasal antihistamines and anti-leukotrienes. Fluticasone propionate is an established INS for the treatment of rhinitis, including SAR. Its favorable pharmacological profile combining high local efficacy with low systemic bioavailability has established fluticasone propionate as an effective intervention. The more recent introduction of structurally related fluticasone furoate with similar but enhanced pharmacological characteristics with a novel delivery device may confer further therapeutic advantages.

Keywords: seasonal allergic rhinitis, fluticasone furoate, fluticasone propionate

\section{Seasonal allergic rhinitis}

Allergic rhinitis is a highly prevalent chronic condition, which presents an enormous global health burden. It is estimated that at least 500 million individuals have allergic rhinitis (AR) and it is one of the most common reasons for attendance with a primary care practitioner. ${ }^{1}$ The nasal manifestations of AR are congestion, rhinorrhea, itching and sneezing. Ocular symptoms occur in at around $70 \%$ of individuals with seasonal allergic rhinitis (SAR), so it is more appropriate to use the term allergic rhinoconjunctivitis. The ocular manifestations are watery eyes, itching, burning (irritability), redness and injection of the conjunctiva and sometimes periorbital edema. In Europe, $71 \%$ of patients experience both nose and eye symptoms and up to $33 \%$ of these are moderate or severe. ${ }^{2}$

The relationship between nasal-ocular symptoms and seasonal allergen exposure plus demonstration of IgE-specific sensitization is diagnostic of SAR.

Seasonal allergic rhinitis (SAR) or hay fever (termed 'spring catarrh' back in the 19th century) has rapidly increased in prevalence in the last 50 years, particularly in the developed world..$^{3-5}$ A recent multi-center study involving 33 centers in Europe demonstrated sensitization to grass pollen (predominantly timothy grass) with a median prevalence of $16.9 \%$, just behind sensitization to house dust mite (Dermatophagoides pteronyssinus) at $21.7 \% .^{6}$

Rhinitis is also defined in the 'allergic rhinitis and its impact in asthma' (ARIA) document in terms of the duration of symptoms (ie, intermittent versus persistent) and effects on quality of life (QOL), thus aiding treatment decisions. ${ }^{1}$ However, given 
the spectrum of respiratory disease that can present with rhinitis symptoms ${ }^{7}$ and the possible use of allergen specific immunotherapy, retention of the key term seasonality is very useful in the diagnostic algorithm and has been retained by several guidelines and standards of care documents. ${ }^{8}$

\section{Mechanisms of allergic rhinitis}

The basic concepts that underlie allergic inflammation are outlined. Antigen presenting cells (APC) take up allergen, which has reached the nasal mucosa. Dendritic cells in particular present processed allergen peptides in the context of MHC Class II to naïve and antigen-specific memory $\mathrm{T}$ cells, leading to a Th2 polarized response in atopic individuals. Allergen specific IgE is tightly held on the surface of resident mast cells that express the high affinity (FceRI) IgE receptor. This is allergen sensitization. Subsequent allergen impaction on the nasal mucosal surface leads to solubilization and diffusion across to sites of mast cell (MC) residence. Cross-linking of two or more affinity $\mathrm{IgE}$ molecules in response to allergen binding leads to $\mathrm{MC}$ activation, degranulation, and release of mediators such as histamine, leukotrienes and neuropeptides, initiating an inflammatory signaling cascade. Rapid neuronal activation and vascular leakage are manifest by almost instantaneous sneezing, nasal itch and congestion. Release of pre-formed key cytokines such as interleukin (IL)-13 contribute to mucus hypersecretion and together with IL-5 and IL-4 drive further cellular recruitment and sustain the inflammatory response. Intense cellular infiltration is associated with further priming of the upper airway innate and adaptive immune responses along with structural cell activation (epithelium and submucosal fibroblasts) and enhanced local IgE production. ${ }^{9}$ This leads to a primed and rapid immune response on further allergen exposure that contributes to the severity and chronicity of symptoms. Ocular symptoms can be particularly troublesome in SAR. ${ }^{10}$ Whilst some of these relate to direct allergen impaction on the eye with local mast cell degranulation and initiation of immune signaling cascades, deposition of allergen in the nasal mucosa alone can activate ocular responses termed the 'the naso-ocular reflex'. ${ }^{11}$ Steroids attenuate key aspects of this allergen-induced inflammatory process. The clinical translation is effective therapeutic intervention.

\section{Treatment of allergic rhinitis}

Oral and intranasal antihistamines, mast cell stabilizers, leukotriene inhibitors, decongestants and intranasal anticholinergics, in addition to intranasal steroids, are all established evidence-based therapeutic interventions for AR. ${ }^{1}$ They are not equally effective ${ }^{12}$ and INS on meta-analyses are significantly more effective than oral or intranasal antihistamines and anti-leukotrienes and equal to the combination of anti-histamine plus anti-leukotriene. ${ }^{13-15}$

For mild disease either a second-generation antihistamine or topical nasal corticosteroid (INS) is recommended. ${ }^{1,16}$ For moderate to severe disease or when nasal congestion is predominant, INS are first line treatment. ${ }^{17,8}$ For the majority of patients with allergic rhinoconjunctivitis, intranasal steroids remain the most effective treatment since all of the major symptoms associated with AR are effectively attenuated.

An important aspect is the effect of upper airway inflammation on lower airway symptoms. It is often not recognized by the respiratory community that up to $80 \%$ individuals with asthma have rhinitis. ${ }^{18} \mathrm{SAR}$ is commonly associated with seasonal allergic asthma, and with demonstrable increases in airway hyper-responsiveness (AHR) that can translate into asthma exacerbation. ${ }^{19}$ Intranasal steroids alone can prevent this seasonal increase in AHR and symptoms. ${ }^{20}$ Intranasal steroid can be more effective in this respect than inhaled corticosteroids. ${ }^{21,22}$

\section{Efficacy and compliance}

For any drug to have significant impact upon a disease, it must demonstrate clinical efficacy, an excellent safety profile and must be used appropriately. Minimal dosing frequency and ease of delivery device will promote compliance with therapy. Important pharmacological characteristics for a topical steroid are a high affinity for the target tissue and steroid receptor with subsequent slow dissociation, ensuring maximal and prolonged local tissue effects. This will also decrease potential systemic effects by delayed release from target tissue. Given that more than $80 \%$ of any nasal steroid is swallowed, a molecule that is either minimally absorbed from the gastrointestinal tract and/or undergoes maximal hepatic first-pass metabolism will substantially decrease systemic bioavailability. The development of intranasal steroids is one of the best examples of molecular modification of a compound to achieve the best therapeutic index.

\section{The emergence of intranasal steroids}

The steroid compounds cortisol and cortisone were first identified from the adrenal cortex in the late $1930 \mathrm{~s} .{ }^{23}$ With the realization that these were potent anti-inflammatory agents, ${ }^{24}$ methods of producing large amounts of synthetic cortisone were sought. However, it became evident that 
both cortisone and cortisol induced clinically significant adverse effects such as severe electrolyte disturbances that limited the dose and duration of use. The development of compounds that utilized the anti-inflammatory potency of cortisone without the systemic effects was urgently required. Structure - activity relationship to absorption, distribution, metabolism and elimination of steroid compounds could be demonstrated. Functional modification of the steroid structure generated compounds with increased activity and improved safety profile. ${ }^{25}$

Target-specific delivery is still the most effective strategy to minimalize systemic effects of any drug, yet it was not until the early 1970 s that attempts to deliver airway-specific steroid in the form of beclomethasone dipropionate (BDP) for asthma were undertaken. ${ }^{26}$ The first intranasal delivery of BDP for SAR was in $1973^{27}$ and BDP remains the most clinically used steroid formulation. Seven further licensed intranasal preparations are currently available: flunisolide (since 1976), ${ }^{28}$ budesonide since the early $1980 \mathrm{~s},{ }^{29}$ fluticasone propionate (FP) and triamcinolone acetonide since the early 1990s. ${ }^{30,31}$ Trials with ciclesonide were first published in 1999 and mometasone furoate since $1996 .^{32,33}$ Fluticasone furoate (FF) was launched in 2009. Each corticosteroid is defined by a specific pharmacokinetic and pharmacodynamic profile. The early market entry of FP with the demonstration of high clinical efficacy and negligible oral bioavailability established it as a key therapeutic intervention in AR and asthma. Fluticasone furoate (FF) is an evolution of FP and there are reports of therapeutic advantages over FP.

\section{Structure-activity relationship}

Cortisol is a natural steroid with potent glucocorticoid and mineralocorticoid action. Four carbon rings (3 rings with 6 carbons and 1 ring with only 5 carbons define the structure) (Figure 1A). In addition there is a $11 \beta$-hyroxyl group that is essential for the glucocorticoid and anti-inflammatory effect of the molecule. All corticosteroids maintain this core structure and the 4,5-carbon unsaturated double bond and the 3-carbon position keto-group are considered essential for bioactivity (Figure 1A). Manipulation of the structural attachments in the 5-carbon ring has allowed manufacture of synthetic corticosteroids with characteristic profiles. The addition of a double bond to the 1,2-carbon position of the first ring increased glucocorticoid potency and decreased metabolism (Figure 1B). The introduction of halogenation at specific points of the molecule increased both the glucocorticoid and mineralocorticoid effects. ${ }^{34} \mathrm{FP}$ is halogenated at both the $6 \alpha$ and the $9 \alpha$ position. ${ }^{35}$ Adding a methyl group to the 16 -carbon position abolished mineralocorticoid activity. Topical potency was increased by adding an esterified lipophilic group to the 5 -carbon ring $(17 \alpha)$ position. ${ }^{36,37}$ Such halogenation was associated with an almost 7-fold increase in binding affinity for the glucocorticoid receptor. ${ }^{38}$ Lipophilicity of the compound is correlated with tissue absorption and retention. ${ }^{37}$

\section{Mechanism of action of steroids in airway inflammation}

Glucocorticoids work by penetrating the plasma membrane of the cell and by binding to the cytosolic glucocorticoid receptor (GR). In humans a single GR gene transcribes two separate receptors GR-alpha $(\alpha)$ and GR-beta $(\beta)$. GR- $\alpha$ is ubiquitously expressed and is considered the key GR in anti-inflammatory responses. Upon GR binding, the

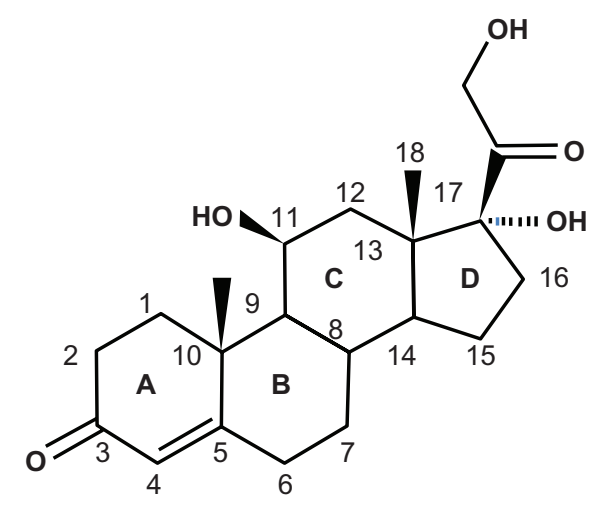

A. Cortisol

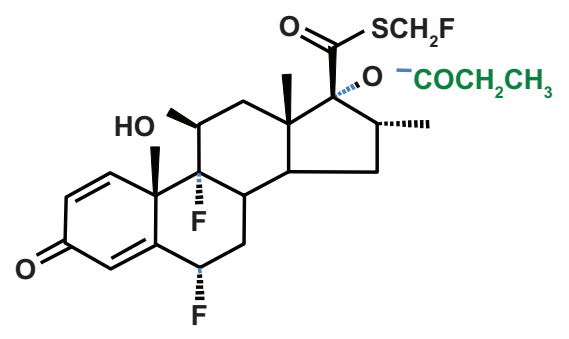

B. Fluticasone Propionate (FP)

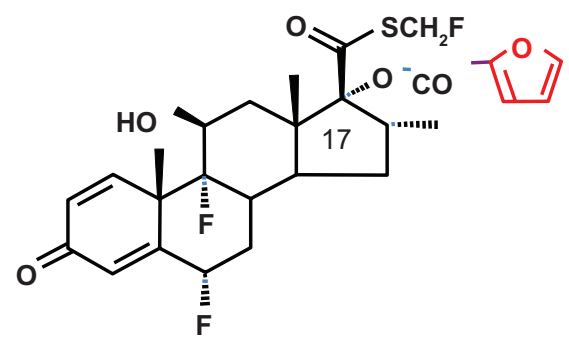

C. Fluticasone Furoate (FF)

Figure I Structure of cortisol with the nomenclature of the steroid molecule outlined (IA). The structure of fluticasone propionate (FP) (IB) and fluticasone furoate (IC). 
GC-GR complex translocates into the nucleus. Repression of inflammatory gene activation is achieved through several heterogeneous mechanisms. The GC-GR complex binds DNA at the glucocorticoid response elements (GRE) in the $5^{\prime}$-upstream region of the steroid responsive genes. Transcriptional activation of anti-inflammatory genes or repression of pro-inflammatory ones can now occur. Other mechanisms of regulating inflammation are via protein protein sequestration via binding to other pro-inflammatory transcription factors such as activator protein (AP-1), leading to the inhibition of the transcription of inflammatory genes. The GC-GR complex can also act indirectly via the induction of inhibitory proteins, for example I $\mathrm{B}$ that suppresses NF- $\kappa \mathrm{B}$ activity. ${ }^{39}$ Although GR- $\beta$ expression has been demonstrated in asthma and nasal polyposis, particularly in relation to inflammatory cells, its role remains uncertain.

\section{Fluticasone propionate}

Fluticasone propionate is a topically active corticosteroid with established efficacy in seasonal and perennial AR. The excellent pharmacodynamic and pharmacokinetic properties along with safety have given FP a key position as one of the market leaders. This impressive therapeutic and safety profile is a reflection of its rapid and extensive uptake by airway tissue, marked affinity for the GR and almost undetectable systemic bioavailability. ${ }^{40}$

The propionate ester side chain renders FP highly lipophilic. Such lipophilicity is a key determinant of its pharmacological profile and allows the drug to bind tissue rapidly and strongly with more prolonged retention than more hydrophilic molecules such as budesonide and hydrocortisone. ${ }^{41}$ Potency and hence therapeutic efficacy is further determined by the GR binding affinity. The greater the steroid - receptor affinity the longer is the binding time and hence transcriptional regulation of genes and protein interactions. Binding studies using competition assays and in vitro binding kinetic studies have confirmed the high selectivity and affinity of FP for the GR receptor. FP demonstrates a high association rate constant and a pronounced low dissociation constant predicting an equilibrium dissociation constant $(\mathrm{Kd})$ (ie, the propensity of the GC-GR complex to dissociate) of $0.49 / 0.51 \mathrm{nmol} / \mathrm{L}$ compared to the $\mathrm{Kd}$ of dexamethasone at 9.36/8.80 nmol/L. The relative receptor affinity (RRA) of FP to the human GR (compared relative to dexamethasone with an RRA of 100) is 1910/1775..$^{41,42}$ These data are summarized in Table 1. Such a fast association, high receptor affinity and subsequent low dissociation predicts clinical efficacy and the long half-time
Table I Summary of glucocorticoid receptor (GR) binding kinetics of fluticasone propionate and fluticasone furoate relative to dexamethasone (Dex) $)^{42}$

\begin{tabular}{lll}
\hline Glucocorticoid & $\begin{array}{l}\text { Fluticasone } \\
\text { propionate (FP) }\end{array}$ & $\begin{array}{l}\text { Fluticasone } \\
\text { furoate (FF) }\end{array}$ \\
\hline Kd & $0.5 \mathrm{I} \mathrm{nmol} / \mathrm{L} \pm 0.03$ & $\begin{array}{l}0.3 \mathrm{nmol} / \mathrm{L} \pm 0.02 \\
(\mathrm{Dex}=8.8 \mathrm{nmol} \pm 0.4 \mathrm{I})\end{array}$ \\
$\mathrm{RRA}(\mathrm{GR})$ & $\mathrm{I} 775 \pm \mathrm{I} 30$ & $\begin{array}{l}2989 \pm \mathrm{I} 55 \\
(\mathrm{Dex}=100 \pm 5)\end{array}$ \\
Systemic & $0.5 \mathrm{I} \%$ & $0.5 \%$ \\
bioavailability & $(800 \mu \mathrm{g} 3$ times daily $)$ & $(880 \mu \mathrm{g}$ at bedtime $)$ \\
\hline
\end{tabular}

Notes: values are presented as the mean and standard deviation of the mean. The average systemic bioavailability of FP and FF relative to the intranasal dose administered is given. ${ }^{43,58}$

Abbreviations: $\mathrm{Kd}$, equilibrium dissociation constant; RRA, relative receptor affinity.

of the FP-GR complex supports the practicality of using once-daily dosing schedules.

The systemic availability of intranasal FP is very low when using standard dosing regimens that the plasma concentration of FP is often below the limit of detection. Using a higher dosing schedule of up to 12 times the normal dose and a more sensitive detection procedure, the mean absolute bioavailability for FP intranasal drops and spray was $0.06 \%$ and $0.51 \%$, respectively, of the administered dose. ${ }^{43}$ Thus the data related to the pharmacokinetics of intranasal FP are limited and much of the information we have is related to studies using either oral or intravenous dosing regimes. Even with oral doses of $10 \mathrm{mg}$ twice daily, the systemic bioavailability of FP was less than $1 \% .{ }^{44}$ Following intravenous administration at a dose range of 0.25 to $1 \mathrm{mg}$, FP demonstrated extensive tissue distribution with a mean residence time of 4.9 hours and rapid tissue clearance with the elimination half-life measured at 7.8 hours. ${ }^{45}$ Oral bioavailability of FP is almost absent due to poor gut absorption and extensive hepatic first pass metabolism ${ }^{46}$ such that any systemic concentrations of intranasal FP will be as a result of absorption via the nasal mucosa. Given that a significant proportion of inhaled nasal steroids will be swallowed, FP will have negligible systemic availability and thus predictably have no bio-systemic effects. FP has a rapid rate of systemic clearance with oral doses of up to 1 to $16 \mathrm{mg}$ becoming undetectable in blood 6 hours after administration. Intravenous administration was associated with clearance rates that approximated hepatic blood flow consistent with extensive hepatic first pass metabolism. ${ }^{47}$ During hepatic metabolism, FP undergoes de-esterification with cleavage of the fluromethylthioester group at the $17 \beta$ position to the $17 \beta$-carboxylic acid. ${ }^{46}$ This inactivates the glucocorticoid molecule before its release into the systemic circulation. There 
does not appear to be any saturation of this process even at oral doses of $4000 \mu \mathrm{g}$. Oral FP is excreted predominantly via the gut in the range of $87 \%$ to $100 \%$, up to $40 \%$ as the $17 \beta$-carboxylic acid metabolite. Less than $5 \%$ is removed in the urine with around $18 \%$ as the $17 \beta$-carboxylic acid. ${ }^{47}$

\section{Therapeutic efficacy in seasonal allergic rhinitis}

Several large, double-blind, placebo-controlled studies have established the clinical efficacy of FP in SAR. An initial dose-ranging study established that $25 \mu \mathrm{g}, 100 \mu \mathrm{g}$ and $400 \mu \mathrm{g}$ given on a twice-daily regime had superior clinical efficacy compared to placebo and this was evident as early as 3 days into dosing. ${ }^{30}$ Subsequent studies evaluated clinical efficacy and the further safety of FP. A study of adults with SAR in season evaluated FP aqueous nasal spray using either $200 \mu \mathrm{g}$ daily versus $100 \mu \mathrm{g}$ twice daily ${ }^{48}$ Both regimes led to significant improvements in total symptom reduction with no significant difference between them. However, a significant reduction in nasal obstruction only was demonstrated for $100 \mu \mathrm{g}$ twice daily rather than $200 \mu \mathrm{g}$ once daily in the 1 -study of 4 weeks' duration. ${ }^{48}$ In the same study, only the $100 \mu \mathrm{g}$ twice-daily regime demonstrated a statistically significant reduction in the use of rescue medication compared to placebo. A significant proportion of individuals continue to have severe SAR despite intervention with intranasal steroids. Given the encouraging safety profile from the earlier dose-ranging studies, several groups investigated whether doubling the doses of FP would confer any further impact on disease. A single-center study enrolling 90 volunteers with more severe SAR demonstrated that $200 \mu \mathrm{g}$ twice daily versus $200 \mu \mathrm{g}$ once daily leads to a significant improvement in the number of symptom free days without nasal itching and conjunctivitis. ${ }^{49}$ Although an important trend in the overall reduction of symptom scores was demonstrated here, significant reduction of the individual symptom score was seen only for nasal itch. ${ }^{49}$ In a separate study, individuals with severe SAR uncontrolled with $200 \mu \mathrm{g}$ of FP once daily over 2 weeks were then randomized to $200 \mu \mathrm{g}$ twice daily for a further 2 weeks. $^{50}$ This conferred a statistically significant advantage with increased symptom-free days in terms of decreased nasal congestion on waking and in the daytime. Although there were improvements in rhinorrhea, sneezing and nasal itch these were not statistically significant.

Response to treatment can also be assessed in terms of rescue medication use. FP at either $100 \mu \mathrm{g}$ twice daily or $200 \mu \mathrm{g}$ once a day confers a significant advantage over placebo in all studies in reducing rescue medication. Although $100 \mu \mathrm{g}$ twice daily appears to confer an advantage over $200 \mu \mathrm{g}$ once daily in at least 2 studies, ${ }^{48,49}$ a total daily dosage higher than $200 \mu \mathrm{g}$ of FP does not confer any further advantage in this respect. FP $200 \mu \mathrm{g}$ provided significant symptom relief in SAR even when used on an 'as needed basis'. ${ }^{51}$ The pooled data from studies predict the onset of therapeutic effect of FP to be within 12 hours after intranasal administration. ${ }^{52}$ Once-daily dosing with FP at either $100 \mu \mathrm{g}$ or $200 \mu \mathrm{g}$ confers similar clinical efficacy both superior to placebo in children 4 to 12 years of age and adolescents with SAR. ${ }^{53-55}$ In clinical practice, FP is prescribed at $100 \mu \mathrm{g}$ into each nostril once a day, which is an effective dose for most individuals with AR. With more severe disease, particularly nasal congestion, it is common practice to use a twice-daily regime with $200 \mu \mathrm{g}$ until control is achieved. It is safe to use higher doses of up to $400 \mu \mathrm{g}$, the standard dose per unit contained with FP nasule (drop) preparations in individuals with severe disease. ${ }^{56}$ The bioavailability of the intranasal drops formula is estimated to be 8 times lower than the equivalent dose of the nasal spray formulation. ${ }^{43}$

\section{Fluticasone furoate}

Fluticasone furoate is a new topical corticosteroid with a licence for the treatment of both seasonal and perennial AR. It is delivered as a well-dispersed mist composed of fine droplets of particles 20 to $50 \mu \mathrm{m}$ in diameter, probably leading to an even area of distribution over the nasal mucosa. ${ }^{57}$ FF is a trifluorinated molecule that is similar in structure to FP other than the addition of a furoate ester to the $17 \alpha-\mathrm{OH}$ group (Figure 1B). In FP, this location is esterified with propionic acid (Figure 1B). Given the structural homology, one would predict a similar pharmacokinetic and pharmacodynamic profile and therapeutic efficacy of FF to FP. In fact, the emerging evidence suggests that FF may have a superior product profile and enhanced clinical efficacy in AR. ${ }^{57}$

As with FP, FF demonstrates a high lipophilicity with a remarkably fast association with the glucocorticoid receptor and a subsequently slow dissociation rate. The propensity of the GC-GR to dissociate, expressed as the $\mathrm{Kd}$, is $0.3 \mathrm{nmol} / \mathrm{L}$ for $\mathrm{FF}$. For comparision the $\mathrm{Kd}$ of dexamethasone was $8.8 \mathrm{nmol} / \mathrm{L}, \mathrm{Kd}$ of FP $0.51 \mathrm{nmol} / \mathrm{L}$ and the $\mathrm{Kd}$ of mometasone furoate (MF) $0.41 \mathrm{nmol} / \mathrm{L}$ in this particular set of experiments (Table 1$).{ }^{42}$ The relative receptor affinity (RRA) of FF to the GR has been shown to be 2989, compared to dexamethasone with an RRA at 100, and with FP and MF at 1775 and 2244 respectively. ${ }^{42}$ The difference in the RRA between FF and FP reflects the potent effects of ester-furoylation at the $17 \alpha-\mathrm{OH}$ location. The $17 \alpha$-furoate ester substitute allows the FF molecule to fully occupy the GR $17 \alpha$-pocket. Such molecular intimacy will allow additional 
structures of the fluticasone core to further interact with the receptor. In vitro data demonstrate enhanced activity of FF for the GR with potent activation of the glucocorticoid response element pathway along with repression of NF- $\mathrm{KB}$ induction of transcriptional events. Almost complete abolition of eosinophil influx into the airway in an animal model of allergic inflammation could be demonstrated with an intratracheal FF dose of only $30 \mu \mathrm{g} .{ }^{57}$ Detection of plasma FF following intranasal dosing was again below the level of detection with even up to doses of $880 \mu \mathrm{g}$ per day and the average absolute bioavailability following intranasal administration was only $0.5 \%{ }^{58}$ As with FP, extensive hepatic first pass metabolism of FF via the cytochrome P450 3A4 enzyme system limits oral bioavailability. ${ }^{46,59}$ Thus FF presents an impressive pharmacodynamic profile compared to the other new generation glucocorticoids. Rapid high affinity binding along with prolonged tissue retention, and minimal systemic availability markets FF is an attractive option for topical therapy.

\section{Seasonal allergic rhinitis}

Four double-blind placebo-controlled studies have been conducted on FF in adults and children over 12 years of age with SAR. One was a dose ranging study to evaluate the efficacy and safety of FF at $55 \mu \mathrm{g}, 110 \mu \mathrm{g}, 220 \mu \mathrm{g}$ and $440 \mu \mathrm{g}$ once daily in the US mountain cedar pollen season. ${ }^{60}$ Although all doses other than $55 \mu \mathrm{g}$ demonstrated similar clinical efficacy that was statistically significant compared to placebo, it was the $110 \mu \mathrm{g}$ dose that was thought to offer the optimal therapeutic ratio and was chosen for further clinical evaluation. Three phase III studies assessed the clinical efficacy and safety of once daily FF at $110 \mu \mathrm{g}$ at the height of season for European grass pollen, US ragweed and US mountain cedar. ${ }^{61,62,63}$ In total 1142 volunteers with SAR were randomized to either $110 \mu \mathrm{g}$ of FF $(n=571)$ or placebo $(n=570)$ in season. Summated data from these studies confirmed the onset of efficacy of FF to be within 24 hours of the initial dosing. Each study demonstrated significant improvement in clinical parameters assessed related to nasal and ocular symptoms. As well as improvement in the reflective total nasal symptom scores (rTNSS), there was also significant improvement in the instantaneous iTNSS (iTNSS) recorded each day just prior to dose administration. This confirmed that a once-daily dosing is efficacious for the entire 24-hour period. Currently the recommended starting dose of FF in adults and children over 12 years of age is $110 \mu \mathrm{g}$ daily per nostril, with the aim of reducing to $55 \mu \mathrm{g}$ once daily once symptom control has been achieved.

An impressive finding from these studies was the consistent efficacy of FF treatment on reducing ocular manifestations in SAR. Symptom reduction was associated with increased positive scoring in the rhinoconjunctivitis quality of life questionnaire (RQLQ). Ocular symptoms of allergy can be particularly troublesome for the patient, are often difficult to treat and therefore represent an unmet clinical need. Although other INS demonstrate some effect on the ocular symptoms of SAR, this efficacy has not always been reproducible. ${ }^{64}$ Studies with FF demonstrate consistency and reproducibility in reduction of ocular symptoms. ${ }^{64}$ It is presumed the effect of intranasal steroids on eye manifestations of allergy is related to the effects of decreased inflammatory mediators that prime nasal neurogenic tissue and initiate the nasal - ocular reflex..$^{1,65}$ The high affinity of FF for the glucocorticoid receptor and slow dissociation rate probably give FF superiority in terms of attenuation of inflammation, ${ }^{66}$ which may reduce neuronal activation. ${ }^{67}$

The experience of FF for SAR in children is limited at present to a single study of either $55 \mu \mathrm{g}$ or $110 \mu \mathrm{g}$ once daily versus placebo in 554 children aged between 2 and 11 years of age over 2 weeks. ${ }^{68}$ Clinical efficacy was most evident only at the $110 \mu \mathrm{g}$ dose. Despite these findings caution is still advised with children and the recommended starting dose of FF for children 2 to 11 years of age is $55 \mu \mathrm{g}$ per daily dose, increasing to $110 \mu \mathrm{g}$ daily only for non-responders or during exacerbation periods.

\section{Safety and adverse events}

The term steroid is associated with apprehension of adverse systemic effects by both clinicians and patients. In particular, concerns over effects on hypothalamic - pituitary - adrenal (HPA) suppression, bone growth and density, posterior sub-capsular cataract formation and raised ocular pressure associated with systemic administration of steroids have often been incorrectly extrapolated to locally delivered steroids, regardless of specific formulation, dosage and site of administration. This has led to poor adherence and treatment failure. ${ }^{69}$ Generally, studies in children and adults have consistently failed to demonstrate any clinically significant effect on the HPA-axis, ${ }^{70}$ bone growth or cataract formation/glaucoma. This is a reflection of low systemic bioavailability following intranasal administration. Clinical guidelines provide reassurance. ${ }^{17}$ The high therapeutic index of both FP and FF predicted by the key pharmacological properties has been borne out by the detailed clinical safety studies of these products.

Safety of FP was established early on. In the initial dose-ranging study, even with the highest dose of $400 \mu \mathrm{g}$ twice-daily there were no increased side effects versus placebo for FP. ${ }^{30}$ Although only a 2-week dosing period was 
used, no HPA axis effects were demonstrated. The safety and tolerance of FP in doses of $50 \mu \mathrm{g}, 200 \mu \mathrm{g}$ or $800 \mu \mathrm{g}$ twice daily over a 4-week period in patients with SAR confirmed that even at the highest total dose of $1600 \mu \mathrm{g}$ there were no increased adverse events compared to placebo. ${ }^{71}$ Detailed evaluation of adrenal function in terms of early morning and $\mathrm{ACTH}$-stimulated cortisol and 24-hour urinary cortisol excretion demonstrated no effect of FP. Several other studies using higher than standard doses of FP have failed to demonstrate HPA-axis effects. ${ }^{72,73}$ Studies assessing adverse effects on other body systems are limited. A 12-month study with FP with $200 \mu \mathrm{g}$ daily did not demonstrate any effect on bone density or occurrence of cataract or glaucoma. ${ }^{74}$ A similar open year-long study of $200 \mu \mathrm{g}$ daily showed no ill effects on the nasal mucosa, in fact saccharin clearance was improved following therapy. ${ }^{75}$ Overall there was no increased severity or frequency of adverse events with FP compared to placebo. The pediatric studies were similarly encouraging. Several studies in children 4 to 11 years of age or adolescents 12 to 17 years of age with FP at 100 or $200 \mu \mathrm{g}$ per day over 2 to 12 weeks failed to show any HPA-axis effect or any increased adverse effect compared to placebo. ${ }^{76,77}$

With FF, the dosing study with up to $440 \mu \mathrm{g}$ once daily for 2 weeks in adults with SAR failed to show any effect on HPA function. ${ }^{60}$ A study of longer duration in adults and adolescents with perennial allergic rhinitis also confirmed the long term safety of FF. ${ }^{78}$ Detailed evaluation of FF in children in children 2 to 11 years of age at $110 \mu \mathrm{g}$ daily for 6 weeks, ${ }^{79} 2$ weeks ${ }^{68}$ and 12 weeks $^{80}$ all confirmed an absence of any effect on HPA function. ${ }^{81}$ Effect on bone growth is of particular concern in children. FP at $110 \mu \mathrm{g}$ per day over 2 weeks had no effect on lower leg growth in a 6- to 12-year group over a 2-week period. ${ }^{82}$ Further studies of longer duration are still needed but the safety data of FF in children is encouraging. The European Medicines Agency (EMEA) has granted the licence for the use of FF (Avamys ${ }^{\circledR}$; GlaxoSmithKline) for adults, adolescents from 12 years upward and children from 6 to 11 years only. The US Food and Drug Administration (FDA) agency, however, has improved FF (Veramyst ${ }^{\circledR}$; GlaxoSmithKline) for children from 2 years upwards.

\section{Tolerability and compliance}

No product will have any impact on disease unless the patient group uses it correctly. Tolerability of the product and concordance with therapy is determined to some extent by the ease of delivery, the sensory attributes of the product such as taste along with the convenience of once-daily use and the absence of any adverse events. ${ }^{83-85}$ Ease of any delivery device is dictated by the absence of any complicated priming procedure prior to use. Delivery of a set drug dose independent of the pressure or speed applied by the patient to the device is particularly relevant to a pediatric and elderly population. Clear indication of the remaining amount of available drug in the apparatus simplifies self-management. ${ }^{86}$ Comfort during administration is also important and local adverse events that arise from mechanical nasal irritation such as anterior nasal crusting and bleeding are particularly bothersome, and reported to affect up to $20 \%$ of individuals leading to cessation of therapy. ${ }^{87}$ The association of systemic and dermatological topical steroids with direct connective tissue atrophy has often been incorrectly extrapolated as casual for nasal crusting and bleeding in the nasal mucosa ${ }^{88}$ and has led to patients and on occasions physicians to discontinue treatment. Advice regarding administration to the outer aspect of the nasal lining using two different sites for the two actuations, in order to maximize the area of mucosal contact and avoid septal deposition, is important. A reminder not to sniff the drug back heartily, thus removing it too quickly from nose to the posterior pharynx, should also be given. The drug delivery device and vehicle are therefore essential aspects to consider when prescribing an INS.

Patient preference in regard to specific sensory attributes of a drug may be determinant of adherence to therapy. Important sensory attributes include minimal odor and irritant effect, absent taste and product moistness. It has been shown that the intensity of such sensory components is inversely correlated with preference. ${ }^{84}$ Sensory attributes vary considerably between current market preparations. ${ }^{84,85,89}$ For example triamcinolone acetonide (TAA) demonstrates less odor and taste with no local irritation and has been shown to have a sensory advantage over FP and MF in studies. ${ }^{89,90}$ However, the pharmacokinetic and pharmacodynamic characteristics of TAA would not favor first-line intranasal use. ${ }^{91}$

The established INS are currently delivered using a basic mechanical pump system that delivers a jet or squirt of drug. However, they differ considerably in terms of exact priming procedure, nozzle size and the ability to hit the nasal mucosa without change in head posture. Much of the focus with these products has been with clinical efficacy of the drug, without too much attention to the importance of device design in relation to factors that ensure compliance and patient acceptance. Understanding the importance of the delivery device relative to features that ensure compliance with therapy has led to extensive investment in the design of the delivery device for the newest product FF. The system for FF has an innovative design that is a prime-free device, allows 
easy grip with a side actuation mechanism such that the user's fingers are away from the delivery nozzle when activating the spray. ${ }^{92}$ Abolishing the need for fingers on the nozzle base allow the use of a shorter delivery nozzle, making the device less invasive. Nasal pain, bleeding and crusting from mechanical irritation are important aggravating factors for patients and a less penetrative device may be better tolerated, particularly by children. Parents can more effectively administer the spray to children using a minimum actuation force. The formulation is alcohol free and hence there is less nasal burning and irritation on mucosal deposition.

\section{Conclusion}

Both FP and FF are excellent examples of how an understanding of molecular structure - function relationships can be used to achieve good clinical efficacy without compromising safety. FP is a long established intervention for AR with an excellent therapeutic index. FF represents an advance not simply in how sophisticated molecular modification can further improve pharmacological profile, but also shows the importance of focus on factors that may improve patient tolerability and hence compliance. Such focus should further advance therapeutic intervention for patients with AR.

\section{Disclosures}

GKS has lectured for GSK, and has also served on rhinitis boards and received research finding from GSK.

\section{References}

1. Bousquet J, Khaltaev N, Cruz AA, et al. Allergic Rhinitis and its Impact on Asthma (ARIA) 2008 update (in collaboration with the World Health Organization, GA(2)LEN and AllerGen). Allergy. 2008;63 Suppl 86: $8-160$.

2. Canonica GW, Bousquet J, Mullol J, Scadding GK, Virchow JC. A survey of the burden of allergic rhinitis in Europe. Allergy. 2007;62 Suppl $85: 17-25$.

3. Emanuel MB. Hay fever, a post industrial revolution epidemic: a history of its growth during the 19th century. Clin Allergy. 1988;18:295-304.

4. Strachan DP. Epidemiology of hay fever: towards a community diagnosis. Clin Exp Allergy. 1995;25:296-303.

5. von Mutius E, Weiland SK, Fritzsch C, Duhme H, Keil U. Increasing prevalence of hay fever and atopy among children in Leipzig, East Germany. Lancet. 1998;351:862-866.

6. Bousquet PJ, Chinn S, Janson C, Kogevinas M, Burney P, Jarvis D. Geographical variation in the prevalence of positive skin tests to environmental aeroallergens in the European Community Respiratory Health Survey I. Allergy. 2007;62:301-309.

7. Scadding GK, Kariyawasam HH. Airways disease: just nosing around? Thorax. 2009;64:923-925.

8. Scadding GK, Durham SR, Mirakian R, et al. BSACI guidelines for the management of allergic and non - allergic rhinitis. Clin Exp Allergy. 2008;38:19-42.

9. Rondon C, Fernandez J, Lopez S, et al. Nasal inflammatory mediators and specific IgE production after nasal challenge with grass pollen in local allergic rhinitis. J Allergy Clin Immunol. 2009;124:1005-1011.
10. Ciprandi G, Cirillo I, Vizzaccaro A, Tosca M, Passalacqua G, Pallestrini E, et al. Seasonal and perennial allergic rhinitis: is this classification adherent to real life? Allergy. 2005;60:882-887.

11. Naclerio RM, Pinto J, deTineo M, Baroody FM. Elucidating the mechanism underlying the ocular symptoms associated with allergic rhinitis. Allergy Asthma Proc. 2008;29:24-28.

12. Portnoy JM, Van Osdol T, Williams PB. Evidence-based strategies for treatment of allergic rhinitis. Curr Allergy Asthma Rep. 2004;4:439-446.

13. Weiner JM, Abramson MJ, Puy RM. Intranasal corticosteroids versus oral $\mathrm{H} 1$ receptor antagonists in allergic rhinitis: systematic review of randomised controlled trials. BMJ. 1998;317:1624-1629.

14. Yanez A, Rodrigo GJ. Intranasal corticosteroids versus topical H1 receptor antagonists for the treatment of allergic rhinitis: a systematic review with meta-analysis. Ann Allergy Asthma Immunol. 2002;89:479-484.

15. Wilson AM, O'Byrne PM, Parameswaran K. Leukotriene receptor antagonists for allergic rhinitis: a systematic review and meta-analysis. Am J Med. 2004;116:338-344.

16. Dykewicz MS, Fineman S, Skoner DP, et al. Diagnosis and management of rhinitis: complete guidelines of the Joint Task Force on Practice Parameters in Allergy, Asthma and Immunology. American Academy of Allergy, Asthma, and Immunology. Ann Allergy Asthma Immunol. 1998;81:478-518.

17. Wallace DV, Dykewicz MS, Bernstein DI, et al. The diagnosis and management of rhinitis: an updated practice parameter. J Allergy Clin Immunol. 2008;122:S1-S84.

18. Leynaert B, Neukirch C, Kony S, et al. Association between asthma and rhinitis according to atopic sensitization in a population-based study. J Allergy Clin Immunol. 2004;113:86-93.

19. Madonini E, Briatico-Vangosa G, Pappacoda A, Maccagni G, Cardani A, Saporiti F. Seasonal increase of bronchial reactivity in allergic rhinitis. J Allergy Clin Immunol. 1987;79:358-363.

20. Corren J, Adinoff AD, Buchmeier AD, Irvin CG. Nasal beclomethasone prevents the seasonal increase in bronchial responsiveness in patients with allergic rhinitis and asthma. J Allergy Clin Immunol. 1992;90:250-256.

21. Aubier M, Levy J, Clerici C, Neukirch F, Herman D. Different effects of nasal and bronchial glucocorticosteroid administration on bronchial hyperresponsiveness in patients with allergic rhinitis. Am Rev Respir Dis. 1992;146:122-126.

22. Stelmach R, do Patrocinio TN, Ribeiro M, Cukier A. Effect of treating allergic rhinitis with corticosteroids in patients with mild-to-moderate persistent asthma. Chest. 2005;128:3140-3147.

23. Murray JR. The history of corticosteroids. Acta DermVenereol Suppl (Stockh). 1989;151:4-6.

24. Hench PS, Kendall EC. The effect of a hormone of the adrenal cortex (17-hydroxy-11-dehydrocorticosterone; compound E) and of pituitary adrenocorticotropic hormone on rheumatoid arthritis. Mayo Clin Proc. 1949;24:181-197.

25. Katz M, Gans EH. Topical corticosteroids, structure-activity and the glucocorticoid receptor: discovery and development - a process of "planned serendipity". J Pharm Sci. 2008;97:2936-2947.

26. Brown HM, Storey G, George WH. Beclomethasone dipropionate: a new steroid aerosol for the treatment of allergic asthma. Br Med J. 1972;1:585-590.

27. Mygind N. Local effect of intranasal beclomethasone dipropionate aerosol in hay fever. Br Med J. 1973;4:464-466.

28. Turkeltaub PC, Norman PS, Crepea S. Treatment of ragweed hay fever with an intranasal spray containing fluinsolide, a new synthetic corticosteroid. J Allergy Clin Immunol. 1976;58:597-606.

29. Balle VH, Pedersen U, Engby B. Allergic perennial and non-allergic, vasomotor rhinitis treated with budesonide nasal spray. Rhinology. 1980;18:135-142.

30. Meltzer EO, Orgel HA, Bronsky EA, et al. A dose-ranging study of fluticasone propionate aqueous nasal spray for seasonal allergic rhinitis assessed by symptoms, rhinomanometry, and nasal cytology. J Allergy Clin Immunol. 1990;86:221-230. 
31. Findlay S, Huber F, Garcia J, Huang L. Efficacy of once-a-day intranasal administration of triamcinolone acetonide in patients with seasonal allergic rhinitis. Ann Allergy. 1992;68:228-232.

32. Schmidt BM, Timmer W, Georgens AC, et al. The new topical steroid ciclesonide is effective in the treatment of allergic rhinitis. J Clin Pharmacol. 1999;39:1062-1069.

33. Hebert JR, Nolop K, Lutsky BN. Once-daily mometasone furoate aqueous nasal spray (Nasonex) in seasonal allergic rhinitis: an active- and placebo-controlled study. Allergy. 1996;51:569-576.

34. Bikowski J, Pillai R, Shroot B. The position not the presence of the halogen in corticosteroids influences potency and side effects. J Drugs Dermatol. 2006;5:125-130.

35. Popper TL, Gentles MJ, Kung TT, et al. Structure-activity relationships of a series of novel topical corticosteroids. J Steroid Biochem. 1987;27:837-843.

36. Phillipps GH, Bailey EJ, Bain BM, et al. Synthesis and structure-activity relationships in a series of antiinflammatory corticosteroid analogues, halomethyl androstane-17 beta-carbothioates and -17 betacarboselenoates. J Med Chem. 1994;37:3717-3729.

37. Dahlberg E, Thalen A, Brattsand R, et al. Correlation between chemical structure, receptor binding, and biological activity of some novel, highly active, 16 alpha, 17 alpha-acetal-substituted glucocorticoids. Mol Pharmacol. 1984;25:70-78.

38. Buchwald P. Glucocorticoid receptor binding: a biphasic dependence on molecular size as revealed by the bilinear LinBiExp model. Steroids. 2008;73:193-208.

39. Pujolsa L, Mullol J, Picado C. Glucocorticoid receptor in human respiratory epithelial cells. Neuroimmunomodulation. 2009;16:290-299.

40. Bryson HM, Faulds D. Intranasal fluticasone propionate. A review of its pharmacodynamic and pharmacokinetic properties, and therapeutic potential in allergic rhinitis. Drugs. 1992;43:760-775.

41. Hogger P, Rohdewald P. Binding kinetics of fluticasone propionate to the human glucocorticoid receptor. Steroids. 1994;59:597-602.

42. Valotis A, Hogger P. Human receptor kinetics and lung tissue retention of the enhanced-affinity glucocorticoid fluticasone furoate. Respir Res. 2007;8:54

43. Daley-Yates PT, Baker RC. Systemic bioavailability of fluticasone propionate administered as nasal drops and aqueous nasal spray formulations. Br J Clin Pharmacol. 2001;51:103-105.

44. Falcoz C, Oliver R, McDowall JE, Ventresca P, Bye A, Daley-Yates PT. Bioavailability of orally administered micronised fluticasone propionate. Clin Pharmacokinet. 2000;39 Suppl 1:9-15.

45. Mackie AE, Ventresca GP, Fuller RW, Bye A. Pharmacokinetics of intravenous fluticasone propionate in healthy subjects. $\mathrm{Br} \mathrm{J}$ Clin Pharmacol. 1996;41:539-542.

46. Pearce RE, Leeder JS, Kearns GL. Biotransformation of fluticasone: in vitro characterization. Drug Metab Dispos. 2006;34:1035-1040.

47. Harding SM. The human pharmacology of fluticasone propionate Respir Med. 1990;84 Suppl A:25-29.

48. LaForce CF, Dockhorn RJ, Findlay SR, et al. Fluticasone propionate: an effective alternative treatment for seasonal allergic rhinitis in adults and adolescents. J Fam Pract. 1994;38:145-152.

49. Dolovich J, O'Connor M, Stepner N, Smith A, Sharma RK. Double-blind comparison of intranasal fluticasone propionate, 200 micrograms, once daily with 200 micrograms twice daily in the treatment of patients with severe seasonal allergic rhinitis to ragweed. Ann Allergy. 1994;72:435-440.

50. Pedersen B, Dahl R, Richards DH, et al. Once daily fluticasone propionate aqueous nasal spray controls symptoms of most patients with seasonal allergic rhinitis. Allergy. 1995;50:794-99.

51. Dykewicz MS, Kaiser HB, Nathan RA, et al. Fluticasone propionate aqueous nasal spray improves nasal symptoms of seasonal allergic rhinitis when used as needed (prn). Ann Allergy Asthma Immunol. 2003;91:44-48.

52. Meltzer EO, Rickard KA, Westlund RE, Cook CK. Onset of therapeutic effect of fluticasone propionate aqueous nasal spray. Ann Allergy Asthma Immunol. 2001;86:286-291.
53. Boner A, Sette L, Martinati L, Sharma RK, Richards DH. The efficacy and tolerability of fluticasone propionate aqueous nasal spray in children with seasonal allergic rhinitis. Allergy. 1995;50:498-505.

54. Grossman J, Banov C, Bronsky EA, et al. Fluticasone propionate aqueous nasal spray is safe and effective for children with seasonal allergic rhinitis. Pediatrics. 1993;92:594-599.

55. Munk ZM, Pearlman D, Graft D, et al. Intranasal fluticasone propionate is effective and well-tolerated in adolescents with seasonal allergic rhinitis. Pediatr Asthma Allergy Immunol. 1994;8:39-46.

56. Keith P, Nieminen J, Hollingworth K, Dolovich J. Efficacy and tolerability of fluticasone propionate nasal drops 400 microgram once daily compared with placebo for the treatment of bilateral polyposis in adults. Clin Exp Allergy. 2000;30:1460-1468.

57. Salter M, Biggadike K, Matthews JL, et al. Pharmacological properties of the enhanced-affinity glucocorticoid fluticasone furoate in vitro and in an in vivo model of respiratory inflammatory disease. Am J Physiol Lung Cell Mol Physiol. 2007;293:L660-L667.

58. Allen A, Down G, Newland A, et al. Absolute bioavailability of intranasal fluticasone furoate in healthy subjects. Clin Ther. 2007;29:1415-1420.

59. Hughes SC, Shardlow PC, Hollis FJ, et al. Metabolism and disposition of fluticasone furoate, an enhanced-affinity glucocorticoid, in humans. Drug Metab Dispos. 2008;36:2337-2344.

60. Martin BG, Ratner PH, Hampel FC, et al. Optimal dose selection of fluticasone furoate nasal spray for the treatment of seasonal allergic rhinitis in adults and adolescents. Allergy Asthma Proc. 2007;28:216-225.

61. Fokkens WJ, Jogi R, Reinartz S, et al. Once daily fluticasone furoate nasal spray is effective in seasonal allergic rhinitis caused by grass pollen. Allergy. 2007;62:1078-1084.

62. Kaiser HB, Naclerio RM, Given J, Toler TN, Ellsworth A, Philpot EE. Fluticasone furoate nasal spray: a single treatment option for the symptoms of seasonal allergic rhinitis. J Allergy Clin Immunol. 2007;119:1430-1437.

63. Jacobs R, Martin B, Hampel F, Toler W, Ellsworth A, Philpot E. Effectiveness of fluticasone furoate 110 mug once daily in the treatment of nasal and ocular symptoms of seasonal allergic rhinitis in adults and adolescents sensitized to mountain cedar pollen. Curr Med Res Opin. 2009;25:1393-1401.

64. Keith PK, Scadding GK. Are intranasal corticosteroids all equally consistent in managing ocular symptoms of seasonal allergic rhinitis? Curr Med Res Opin. 2009;25:2021-2041.

65. Baroody FM, Shenaq D, deTineo M, Wang J, Naclerio RM. Fluticasone furoate nasal spray reduces the nasal-ocular reflex: a mechanism for the efficacy of topical steroids in controlling allergic eye symptoms. J Allergy Clin Immunol. 2009;123:1342-1348.

66. Baumann D, Bachert C, Hogger P. Dissolution in nasal fluid, retention and anti-inflammatory activity of fluticasone furoate in human nasal tissue ex vivo. Clin Exp Allergy. 2009;39:1540-1550.

67. Raap U, Braunstahl GJ. The role of neurotrophins in the pathophysiology of allergic rhinitis. Curr Opin Allergy Clin Immunol. 2010;10:8-13.

68. Meltzer EO, Lee J, Tripathy I, Lim J, Ellsworth A, Philpot E. Efficacy and safety of once-daily fluticasone furoate nasal spray in children with seasonal allergic rhinitis treated for 2 weeks. Pediatr Allergy Immunol. 2009;20:279-286.

69. Skoner JD, Schaffner TJ, Schad CA, Kwon AY, Skoner DP. Addressing steroid phobia: improving the risk-benefit ratio with new agents. Allergy Asthma Proc. 2008;29:358-364.

70. Bruni FM, De Luca G, Venturoli V, Boner AL. Intranasal corticosteroids and adrenal suppression. Neuro immuno modulation. 2009;16: $353-362$.

71. van As A, Bronsky E, Grossman J, Meltzer E, Ratner P, Reed C. Dose tolerance study of fluticasone propionate aqueous nasal spray in patients with seasonal allergic rhinitis. Ann Allergy. 1991;67:156-162.

72. Vargas R, Dockhorn RJ, Findlay SR, Korenblat PE, Field EA, Kral KM. Effect of fluticasone propionate aqueous nasal spray versus oral prednisone on the hypothalamic-pituitary-adrenal axis. J Allergy Clin Immunol. 1998;102:191-197. 
73. Haye R, Gomez EG. A multicentre study to assess long-term use of fluticasone propionate aqueous nasal spray in comparison with beclomethasone dipropionate aqueous nasal spray in the treatment of perennial rhinitis. Rhinology. 1993;31:169-174.

74. Howland WC, III. Fluticasone propionate: topical or systemic effects? Clin Exp Allergy. 1996;26 Suppl 3:18-22.

75. Scadding GK, Lund VJ, Holmstrom M, Darby YC. Clinical and physiological effects of fluticasone propionate aqueous nasal spray in the treatment of perennial rhinitis. Rhinol Suppl. 1991;11:37-43.

76. Richards DH, Milton CM. Fluticasone propionate aqueous nasal spray: a well-tolerated and effective treatment for children with perennial rhinitis. Pediatr Allergy Immunol. 1996;7:35-43.

77. Treatment of seasonal allergic rhinitis with once-daily intranasal fluticasone propionate therapy in children. Fluticasone Propionate Collaborative Pediatric Working Group. J Pediatr. 1994;125:628-634.

78. Rosenblut A, Bardin PG, Muller B, et al. Long-term safety of fluticasone furoate nasal spray in adults and adolescents with perennial allergic rhinitis. Allergy. 2007;62:1071-1077.

79. Tripathy I, Levy A, Ratner P, Clements D, Wu W, Philpot E. HPA axis safety of fluticasone furoate nasal spray once daily in children with perennial allergic rhinitis. Pediatr Allergy Immunol. 2009;20:287-294.

80. Maspero JF, Rosenblut A, Finn A Jr, Lim J, Wu W, Philpot E. Safety and efficacy of fluticasone furoate in pediatric patients with perennial allergic rhinitis. Otolaryngol Head Neck Surg. 2008;138:30-37.

81. Meltzer EO, Tripathy I, Maspero JF, Wu W, Philpot E. Safety and tolerability of fluticasone furoate nasal spray once daily in paediatric patients aged 6-11 years with allergic rhinitis: subanalysis of three randomized, double-blind, placebo-controlled, multicentre studies. Clin Drug Investig. 2009;29:79-86.

82. Gradman J, Caldwell MF, Wolthers OD. A 2-week, crossover study to investigate the effect of fluticasone furoate nasal spray on short-term growth in children with allergic rhinitis. Clin Ther. 2007;29:1738-1747.

83. Khanna P, Shah A. Assessment of sensory perceptions and patient preference for intranasal corticosteroid sprays in allergic rhinitis. Am J Rhinol. 2005;19:316-321.
84. Mahadevia PJ, Shah S, Leibman C, Kleinman L, O’Dowd L. Patient preferences for sensory attributes of intranasal corticosteroids and willingness to adhere to prescribed therapy for allergic rhinitis: a conjoint analysis. Ann Allergy Asthma Immunol. 2004;93:345-350.

85. Meltzer EO, Bardelas J, Goldsobel A, Kaiser H. A preference evaluation study comparing the sensory attributes of mometasone furoate and fluticasone propionate nasal sprays by patients with allergic rhinitis. Treat Respir Med. 2005;4:289-296.

86. Bousquet J, Van Cauwenberge P, Bachert C, et al. Requirements for medications commonly used in the treatment of allergic rhinitis. European Academy of Allergy and Clinical Immunology (EAACI), Allergic Rhinitis and its Impact on Asthma (ARIA). Allergy. 2003;58:192-197.

87. Waddell AN, Patel SK, Toma AG, Maw AR. Intranasal steroid sprays in the treatment of rhinitis: is one better than another? J Laryngol Otol. 2003; 117:843-845.

88. Baroody FM, Cheng CC, Moylan B, et al. Absence of nasal mucosal atrophy with fluticasone aqueous nasal spray. Arch Otolaryngol Head Neck Surg. 2001;127:193-199.

89. Stokes M, Amorosi SL, Thompson D, Dupclay L, Garcia J, Georges G. Evaluation of patients' preferences for triamcinolone acetonide aqueous, fluticasone propionate, and mometasone furoate nasal sprays in patients with allergic rhinitis. Otolaryngol Head Neck Surg. 2004;131:225-231.

90. Bachert C, El Akkad T. Patient preferences and sensory comparisons of three intranasal corticosteroids for the treatment of allergic rhinitis. Ann Allergy Asthma Immunol. 2002;89:292-297.

91. Daley-Yates PT, Richards DH. Relationship between systemic corticosteroid exposure and growth velocity: development and validation of a pharmacokinetic/pharmacodynamic model. Clin Ther. 2004;26:1905-1919.

92. Berger WE, Godfrey JW, Slater AL. Intranasal corticosteroids: the development of a drug delivery device for fluticasone furoate as a potential step toward improved compliance. Expert Opin Drug Deliv. 2007;4:689-701.
Journal of Asthma and Allergy

\section{Publish your work in this journal}

The Journal of Asthma and Allergy is an international, peer-reviewed open-access journal publishing original research, reports, editorials and commentaries on the following topics: Asthma; Pulmonary physiology; Asthma related clinical health; Clinical immunology and the immunological basis of disease; Pharmacological interventions and

\section{Dovepress}

new therapies. Issues of patient safety and quality of care will also be considered. The manuscript management system is completely online and includes a very quick and fair peer-review system, which is all easy to use. Visit http://www.dovepress.com/testimonials.php to read real quotes from published authors. 